\title{
Current status and future perspectives of capsule endoscopy
}

\author{
Hyun Joo Song ${ }^{1}$, Ki-Nam Shim ${ }^{2}$ \\ ${ }^{1}$ Department of Internal Medicine, Jeju National University School of Medicine, Jeju, ${ }^{2}$ Department of Internal Medicine, Ewha Womans \\ University School of Medicine, Seoul, Korea
}

Small bowel capsule endoscopy (CE) was first introduced 15 years ago, and a large amount of literature has since been produced, focused on its indication, diagnostic yields, and safety. Guidelines that have made CE the primary diagnostic tool for small bowel disease have been created. Since its initial use in the small bowel, CE has been used for the esophagus, stomach, and colon. The primary indications for small bowel CE are obscure gastrointestinal bleeding, unexplained iron deficiency anemia, suspected Crohn's disease, small bowel tumors, nonsteroidal anti-inflammatory drug enteropathy, portal hypertensive enteropathy, celiac disease, etc. Colon CE provides an alternative to conventional colonoscopy, with possible use in colorectal cancer screening. Guidelines for optimal bowel preparation of CE have been suggested. The main challenges in CE are the development of new devices with the ability to provide therapy, air inflation for better visualization of the small bowel, biopsy sampling systems attached to the capsule, and the possibility of guiding and moving the capsule by an external motion controller. We review the current status and future directions of CE, and address all aspects of clinical practice, including the role of CE and long-term clinical outcomes. (Intest Res 2016;14:21-29)

Key Words: Capsule endoscopy; Intestine, small; Current; Future

\section{INTRODUCTION}

Wireless capsule endoscopy (CE) was invented by Gavriel Iddan in the mid-1990s. ${ }^{1}$ Since its introduction in 2000, CE has revolutionized the diagnosis and treatment of various small bowel diseases. The field of CE has made tremendous advances over the past 15 years, and gastroenterologists have become skilled at advancing flexible video endoscopes into the upper and lower portions of the gastrointestinal (GI) tract. Small bowel CE is the best method for examining the full surface of the small bowel and is optimal for small bowel endoscopic imaging. ${ }^{2}$

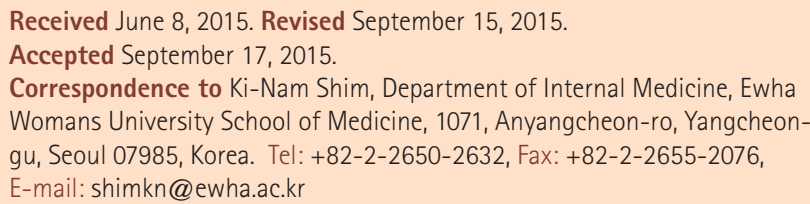

Financial support: None. Conflict of interest: None.
The third-generation capsule was released in August 2014 (PillCam ${ }^{\circledR}$ SB3; Given Imaging, Yokneam, Israel). Other smallbowel capsules have been introduced since 2006 in Korea (MiroCam ${ }^{\circledR}$; IntroMedic, Seoul, Korea), Japan (EndoCapsule $^{\mathbb{R}}$; Olympus, Tokyo, Japan) and China (OMOM${ }^{\mathbb{R}}$; Jinshan Science and Technology Company, Chongqing, China). ${ }^{3}$ A comparison among currently available CE devices is shown in Table $1{ }^{4}$ In a direct comparison in 83 patients, the PillCam and MiroCam showed similar efficacy for obscure gastrointestinal bleeding (OGIB) diagnosis. The study showed satisfactory diagnostic agreement between the two systems $(\kappa=0.66){ }^{5}$ A similar comparison was performed between the MiroCam and the EndoCapsule in 50 patients; no statistical difference was found in their performance and the combined diagnostic yield was 58\%. ${ }^{6}$ Given Imaging has also developed a double-headed esophageal capsule (PillCam Eso3) and a double-headed colonic capsule (PillCam Colon 2).

We review the current status and future directions of CE by addressing all aspects of clinical practice, including the

\footnotetext{
(c) Copyright 2016. Korean Association for the Study of Intestinal Diseases. All rights reserved.

This is an Open Access article distributed under the terms of the Creative Commons Attribution Non-Commercial License (http://creativecommons.org/licenses/by-nc/4.0)

which permits unrestricted non-commercial use, distribution, and reproduction in any medium, provided the original work is properly cited.
} 
Table 1. Comparison Between Currently Available Capsule Endoscopy Systems

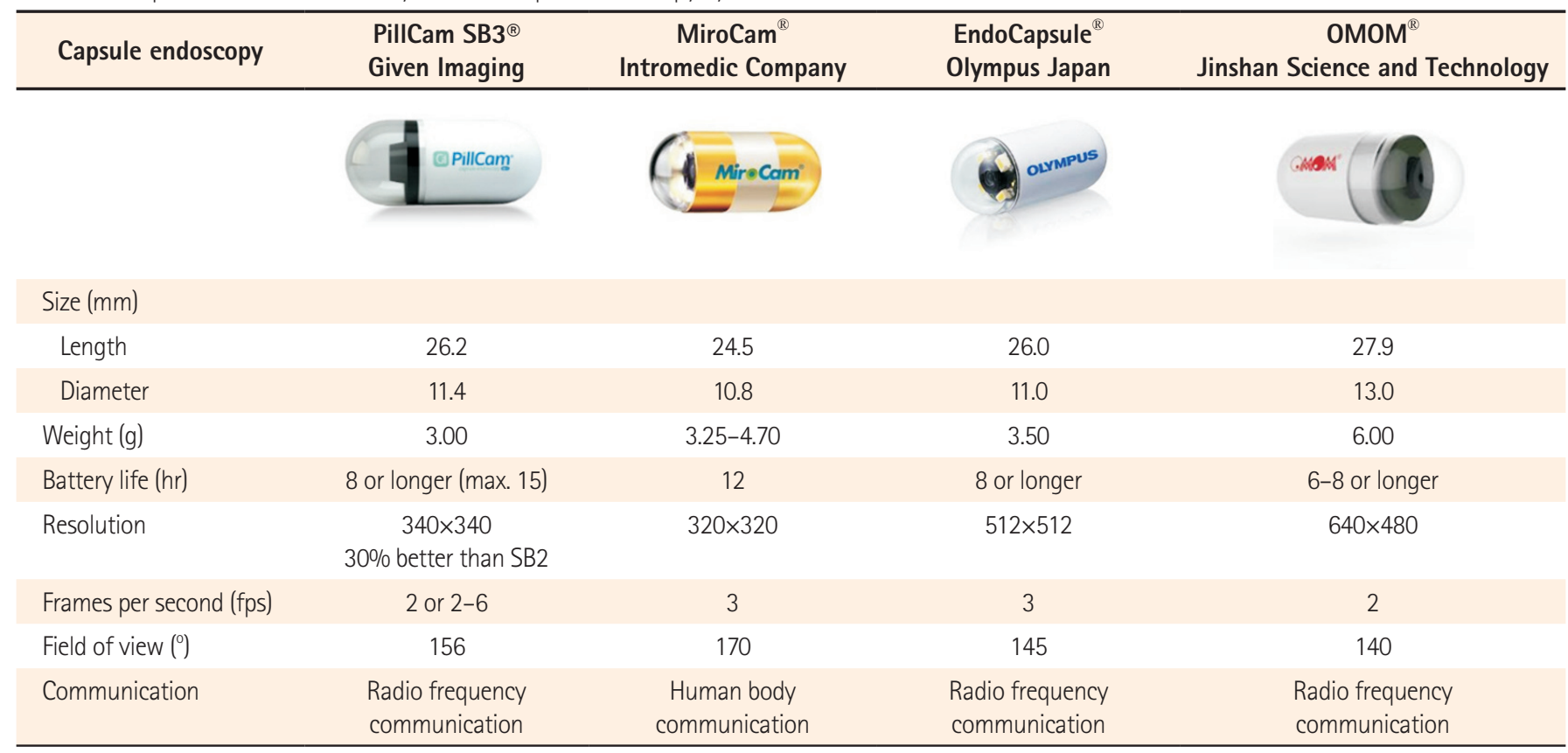

Table 2. Indications and Contraindications for Capsule Endoscopy

\begin{tabular}{ll}
\hline \multicolumn{1}{c}{ Indications } & \multicolumn{1}{c}{ Contraindications } \\
\hline Obscure gastrointestinal bleeding & Absolute contraindications \\
Iron deficiency anemia & Clinical or radiographic evidence of relevant bowel obstruction \\
CD & Extensive and acute CD of the small bowel with obstruction \\
Small bowel tumors & Intestinal pseudo-obstruction \\
NSAID-induced enteropathy & Relative contraindications \\
Portal hypertensive enteropathy & Cardiac pacemakers or other implanted electromedical devices \\
Celiac disease & Dysphagia \\
Inherited polyposis syndromes & Previous abdominal or pelvic surgery \\
Unexplained chronic abdominal pain & Pregnancy \\
& Extensive intestinal diverticulosis \\
\hline
\end{tabular}

role of CE according to 2013 and 2015 Korean Society of Gastroinestinal Endoscopy ${ }^{7-9}$ and 2015 European Society of Gastrointestinal Endoscopy (ESGE) guidelines, ${ }^{10}$ as well as long-term clinical outcomes with special reference to Korean multicenter studies.

\section{INDICATIONS FOR SMALL BOWEL CE}

The major indications for small bowel CE are OGIB, unexplained iron deficiency anemia (IDA), CD, small bowel tumors, NSAID-induced enteropathy, portal hypertensive enteropathy (PHE), celiac disease, inherited polyposis syndromes, chronic abdominal pain, etc. (Table 2). The contra- indications for CE are also presented in Table 2.

\section{OGIB}

OGIB refers to GI bleeding of undetermined origin that persists or recurs despite negative upper GI endoscopy or colonoscopy. Approximately $5 \%$ of GI bleeding cases are attributed to OGIB. ${ }^{11}$ OGIB originates in the small bowel in more than $80 \%$ of cases. ${ }^{12}$ It is "overt" when there are signs of bleeding such as hematochezia or melena; it is "occult" with a positive fecal occult blood test, or when IDA is presumed to be caused by GI blood loss. ${ }^{13}$

The Korean Gut Image Study Group published guidelines 


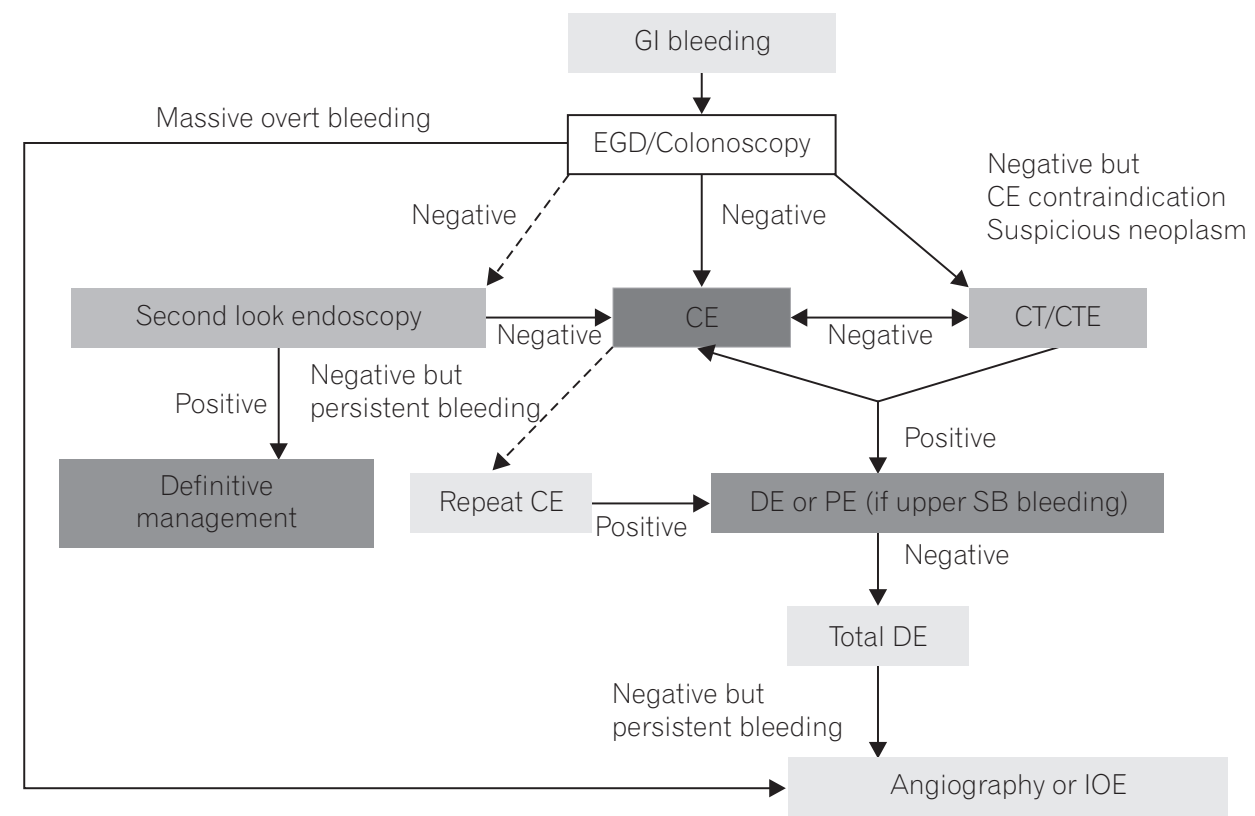

Fig. 1. Korean Gut Image Study Group guidelines for proposed approach to diagnosis and management of obscure gastrointestinal bleeding. 'Dashed arrows indicate less-preferred options. Gl, gastrointestinal; EGD, esophagogastroduodenoscopy; $C E_{1}$ capsule endoscopy; CTE, CT enterography; $D E$, deep enteroscopy; $P E$, push enteroscopy; SB, small bowel; IOE, intraoperative enteroscopy. for OGIB in 2013. ${ }^{7}$ These guidelines proposed methods for diagnosis and management of OGIB (Fig. 1). According to the guidelines, CE is an effective initial diagnostic method for evaluating patients (strong recommendation, moderate quality evidence). Diagnostic yield is improved by performing CE early in OGIB (strong recommendation, moderate quality evidence). The 2015 ESGE guidelines also recommends performing small bowel CE as soon as possible after a bleeding episode, ideally within 14 days, in patients with OGIB (strong recommendation, moderate quality evidence). ${ }^{10}$

A recent Korean multicenter study using a nationwide registry ( $\mathrm{n}=305)$ demonstrated that $\mathrm{CE}$ did not have a significant impact on the long-term outcome of patients with OGIB. ${ }^{14}$ Patients with angiodysplasia on CE or with OGIB for $>3$ months had independent prognostic factors associated with rebleeding. Discontinuation of drugs was necessary to reduce the rebleeding risk in patients who were taking anticoagulants.

CE benefits are visualization of the entire small bowel, noninvasiveness, safety, and high diagnostic yield. Its limitations, however, are that no biopsies accompany the test, accurate location of the source of bleeding can be difficult, and there is a risk of capsule retention. ${ }^{13}$ Compared with CE, double balloon enteroscopy (DBE) is more invasive, can be laborious, and requires sedation. Learning to perform DBE is also time-consuming. ${ }^{15}$ Complications include acute pancreatitis, small bowel perforation, and ileus. ${ }^{16,17}$ The literature also indicates a similar diagnostic yield for CE (62\%) and DBE (56\%). ${ }^{18}$ The diagnostic yield for DBE, however, is significantly higher in patients with a positive vs. negative CE (75.0\% vs. 27.5\%). ${ }^{18}$ According to the Korean Gut Image Study Group guidelines, ${ }^{7}$ CE and DBE provide similar diagnostic yield in patients with OGIB (strong recommendation, low quality evidence). CE is recommended before DBE for the diagnosis of patients with OGIB (strong recommendation, low quality evidence).

\section{IDA}

IDA occurs in $2 \%-5 \%$ of adult males and postmenopausal females in developed countries and is a common reason for referral to gastroenterologists. ${ }^{19}$ In $70 \%-80 \%$ of patients, bidirectional endoscopy identifies the cause of IDA. When this is negative, the small bowel is a possible target for further investigation. ${ }^{19} \mathrm{CE}$ has advantages over barium radiography, enteroclysis, and push enteroscopy, and is better for diagnosing clinically significant small bowel pathology resulting in IDA. In elderly patients with IDA, angioectasia is one of the most commonly identified lesions by $\mathrm{CE}^{20}{ }^{20}$ The diagnostic yield of CE for IDA was reported to progressively increase with age, especially in patients over 85 years of age. In patients with IDA, the ESGE recommends that all the following steps are performed prior to small bowel CE: a complete medical history, upper endoscopy with duodenal and gastric biopsies, and ileocolonoscopy (strong recommendation, low quality evidence).$^{10}$

According to a recent study of CE in premenopausal 
females ( $\mathrm{n}=131)$ with IDA compared with that in males $(\mathrm{n}=118)$ and postmenopausal females $(\mathrm{n}=80)$, diagnostic yield of CE for IDA was $44.6 \%{ }^{21}$ Diagnostic yield was $50.8 \%$ vs. $38.9 \%$ in males vs. females $(P=0.05)$, and was $55.0 \%$ vs. $13.7 \%$ in postmenopausal vs. premenopausal females $(P<0.001)$. In the etiological study of IDA, the diagnostic yield of CE was low in premenopausal females, and there is no cost-effectiveness in relation to clinical impact. The most common findings in the postmenopausal group were angioectasias (70.5\%), and erosions (57.1\%) were most common in the premenopausal group. ${ }^{21}$ Regarding the factors possibly associated with diagnosis of IDA patients, a favorable association between increase in diagnostic yield of CE and age and severity of anemia has been found. ${ }^{22,23}$ However, due to relevant findings in young patients, age cannot be the only criterion for patient selection. ${ }^{24}$

\section{CD}

At present, no index for diagnosis of CD exists. While the presence of clinical symptoms remains an important factor in the diagnostic process, abdominal pain or chronic diarrhea alone rarely lead to identification of clinically significant small bowel lesions on $\mathrm{CE} .{ }^{25}$ More predictive clinical markers of small bowel CD include weight loss, ${ }^{26}$ increased inflammatory markers, ${ }^{27,28}$ perianal disease, ${ }^{29}$ and fecal calprotectin levels. $^{30,31}$

According to the 2015 Korean guidelines, CE is the most accurate diagnostic tool for detecting mucosal lesions in suspected or established CD (strong recommendation, low evidence). ${ }^{9}$ Small bowel radiological examinations or patency capsules are recommended prior to CE for evaluating patients with suspected or established CD (strong recommendation, low quality evidence). In patients highly suspect for $\mathrm{CD}$, CE is a useful diagnostic indicator following negative ileocolonoscopy and small bowel radiologic examination (weak recommendation, low quality evidence).

Ileocolonoscopy is recommended (ESGE 2015) as the first endoscopic examination to investigate patients with suspected CD (strong recommendation, high quality evidence). ${ }^{10} \mathrm{CE}$ is also recommended to rule out $\mathrm{CD}$ in patients with negative ileocolonoscopy and absence of stenosis or obstruction (strong recommendation, moderate quality evidence). Routine small bowel imaging or PillCam ${ }^{\circledR}$ patency capsule use prior to $\mathrm{CE}$ is not recommended (strong recommendation, low quality evidence). A recent prospective study confirmed that CE was superior to small bowel followthrough and the same as ileocolonoscopy in determining small bowel inflammation in patients with suspected CD; this study also suggested that CE can be used to establish the diagnosis of CD in patients with proximal small bowel inflammation, when ileocolonoscopy is negative. ${ }^{32}$

Inflammation, extent of disease, and presence of strictures are three determinants of small bowel pathology in CD. The capsule endoscopy Crohn's disease activity index (CECDAI) score evaluates the proximal as well as distal segments of the small bowel according to capsule transit time, as validated by a recent multicenter prospective study. ${ }^{33,34}$ The Lewis score,${ }^{35}$ the use of which has also recently been validated, ${ }^{36}$ is based on the presence and distribution of ulceration, villous edema, and stenosis. These systems are used for quantitative description of distribution and severity of mucosal lesions, but cannot be used as a diagnostic tool. ${ }^{37}$

Capsule retention risk in patients with suspected CD in the absence of obstructive symptoms or known stenosis without history of small bowel resection is low $(\sim 1.6 \%)$, and comparable to that of OGIB. ${ }^{38-40}$ However, capsule retention risk increases to approximately $13 \%$ in patients with known CD. ${ }^{38-42}$ In $27 \%-40 \%$ of patients with known CD, findings of small bowel stenosis upon CT enterography or MR enterography may preclude subsequent $\mathrm{CE},{ }^{43}$ but not all strictures actually result in significant mechanical obstruction. Therefore, the use of the PillCam ${ }^{\circledR}$ patency capsule may help identify patients at increased risk of capsule retention. ${ }^{44}$ The PillCam ${ }^{\circledR}$ patency capsule is currently not available in Korea, but is expected to be commercially available next year.

\section{Small Bowel Tumors}

Most small bowel tumors are detected during work-up of OGIB or IDA, but represent only about $3.5 \%-5.0 \%$ of these patients. ${ }^{45}$ The 2015 ESGE recommends early use of small bowel CE in the search for a small bowel tumor when OGIB and IDA are not explained otherwise (strong recommendation, moderate quality evidence).$^{10}$ Consideration of DBE is recommended (ESGE) over small bowel CE if prior imaging tests have demonstrated suspicion of small bowel tumor (strong recommendation, low quality evidence).

According to a multicenter Korean study conducted by the Korean Gut Image group, ${ }^{46} \mathrm{CE}$ was used in 57 (4.3\%) of 1,332 patients to diagnose small bowel tumors. OGIB was the most frequent indication for CE in malignant tumors, followed by abdominal pain and weight loss. CE effectively identified small bowel tumors otherwise undetectable by conventional radiological studies (diagnostic impact $=52.6 \%$ ) with significant impact on the therapeutic course (therapeutic impact 
$=12.3 \%)$. Although the manifestations of small bowel tumors are mostly subclinical, small intestinal bleeding might be the most common symptom. CE proved significantly superior in diagnostic accuracy over radiological procedures for small tumors, especially those $1 \mathrm{~cm}$ in size or less. ${ }^{46}$

A retrospective analysis demonstrated that a proposed tumor score composed of mucosal disruption, bleeding, an irregular surface, white villi, and color were helpful to identify small bowel tumors. ${ }^{47}$ Cross-sectional imaging is recommended (ESGE) to determine operability in CE of small bowel tumors of high diagnostic certainty. In indefinite diagnosis of small bowel tumors by CE, biopsy sampling by DBE is required (strong recommendation, low quality evidence). ${ }^{10}$

\section{NSAID-Induced Enteropathy}

The injurious effects of NSAIDs on the small bowel were not fully understood until the widespread use of CE. It is estimated that over two-thirds of regular NSAID users develop small intestinal injuries and that these are more common than gastroduodenal mucosal injuries. Recently, chronic low-dose aspirin consumption was found to be associated with injury to the lower gut and to be a significant contributing factor in small bowel hemorrhage, ulceration, and strictures. ${ }^{48}$ NSAID-induced enteropathy has recently become a topic of great interest to gastroenterologists, as CE and DBE are available for detecting small bowel lesions.

According to a Korean multicenter retrospective study $(\mathrm{n}=140)$ based on the CE nationwide database registry, ${ }^{49}$ the most common findings were multiple ulcerations (58.6\%) and erosions or aphthae (22.9\%). During the follow-up period (mean, 15.9 19.0 months), NSAID-induced small intestinal injury only recurred in six patients $(4.3 \%)$. Older age and hypertension were positive predictive factors for recurrence.

\section{PHE}

PHE is a mucosal abnormality of the small bowel that is observed in cirrhosis patients with portal hypertension. ${ }^{50} \mathrm{~A}$ recent Korean retrospective multicenter study $(\mathrm{n}=45)$ utilizing the Capsule Endoscopy Nationwide Database Registry revealed the prevalence of PHE to be $40 \% .^{51}$ In a comparison of PHE and non-PHE groups, angiodysplasias were found in $55.7 \%$ (vs. $7.4 \%, P=0.001$ ) and varices in $38.9 \%$ (vs. $0 \%$, $P=0.001$ ). Based on abdominal CT findings, six secondary changes due to portal hypertension resulted in a total CT score of $0-6$, with a high CT score ( $\geq 3$ vs. $<3, P=0.004$ ) significantly associated with PHE. Another recent large study $(\mathrm{n}=134)$ reported PHE in $91(68 \%)$ cases, erythema in 70 (52\%), erosions in 25 (19\%), angioectasia in 24 (18\%), villous edema in $18(13 \%)$, and varices in $10(7 \%))^{52}$ Most lesions were located in the jejunum. Clinical characteristics associated with PHE included Child-Pugh grade of B or C, esophageal varices, portal hypertensive gastropathy, portosystemic shunts, ascites, and portal thrombosis. The presence of a portosystemic shunt was an independent predictor of PHE (OR, 3.15; 95\% CI, 1.27-7.95).

\section{Celiac Disease}

Celiac disease is an autoimmune disorder characterized by an increased immunological response to gluten; prevalence rates in American and European populations are estimated at $0.2 \%-1.0 \%{ }^{53,54}$ The usual diagnostic test for celiac disease is upper endoscopy with duodenal biopsies and small bowel histology to demonstrate the presence of villous atrophy (VA). ${ }^{55}$ There has been increasing interest in the role of CE in celiac disease. CE, due to its 8-fold magnification power over the dissecting microscope, can detect VA and other small bowel complications in celiac disease. In studies of the diagnostic utility of CE for VA of celiac disease, the sensitivity, specificity, and positive and negative predictive values of CE were $70 \%-100 \%, 64 \%-100 \%, 96 \%-100 \%$ and $71 \%-93 \%$, respectively ${ }^{56-59}$ It is rare in Asian countries, but a case of a 36-year-old woman was reported in Korea ${ }^{60} \mathrm{CE}$ and enteroscopy showed VA and blunting of villi from the duodenum. Small bowel pathology showed VA with lymphocyte infiltration. However, CE alone is probably insufficient to confirm a diagnosis, as endoscopic markers are not specific to celiac disease. ${ }^{61}$

The use of small bowel CE for suspected celiac disease is strongly discouraged (ESGE); however, CE may be useful in patients unwilling or unable to undergo conventional endoscopy (strong recommendation, low quality evidence). ${ }^{10}$ Small bowel CE is unacceptable in assessing the extent of disease or response to a gluten-free diet (strong recommendation, low quality evidence).

\section{Inherited Polyposis Syndromes}

Surveillance of the proximal small bowel in familial adenomatous polyposis according to ESGE guidelines is best performed by using conventional forward-viewing and sideviewing endoscopes (strong recommendation, moderate quality evidence).$^{10}$ Indications for small bowel investigation in familial adenomatous polyposis include small bowel CE 
and/or cross-sectional imaging techniques for identifying polyps in the rest of the small bowel (ESGE); clinical relevance, however, remains to be demonstrated (weak recommendation, moderate quality evidence).

\section{Unexplained Chronic Abdominal Pain}

CE provides a noninvasive diagnostic tool for patients with unexplained chronic abdominal pain, but the diagnostic yield is limited (20.9\%). Among patients with positive findings, inflammatory lesions are the most common. ${ }^{62}$ According to a Korean multicenter study, diagnostic yield of CE may be increased by abdominal pain accompanied by weight loss. ${ }^{20}$ Multivariate analysis showed weight loss was a significant risk factor for positive findings of CE. However, no relationship was found with ESR, CRP, or albumin level. According to a Greek study of chronic abdominal pain, ${ }^{63}$ the overall diagnostic yield of CE was $44.4 \%$, but was significantly higher in patients with abdominal pain plus positive inflammatory markers, and was $66.7 \%$ for those without diarrhea and $90.1 \%$ for those with diarrhea. In both types of analyses, abnormal CRP and ESR were significantly correlated with positive CE findings.

\section{OPTIMAL BOWEL PREPARATION FOR SMALL} BOWEL CE

During CE, small bowel visualization quality (SBVQ), diagnostic yield, and cecal completion rate (CR) are influenced by several factors, including air bubbles, food material in the small bowel, and delayed gastric and small bowel transit time. Therefore, bowel preparation before $\mathrm{CE}$ is as essential as bowel preparation before colonoscopy. The Korean Gut Image Study Group published guidelines for bowel preparation in 2013. ${ }^{8}$ According to the guidelines, polyethylene glycol (PEG) bowel preparation enhances diagnostic yield and SBVQ, without effect on cecal CR. A 2-liter PEG solution bowel preparation is similar to that of a 4-L PEG solution in diagnostic yield, SBVQ, and CR of CE. Bowel preparation by fasting or PEG solution, when combined with simethicone, enhances SBVQ, but does not affect CR of CE. Bowel preparation using prokinetics does not enhance the SBVQ, diagnostic yield, or CR of CE. A 2-L PEG-based purge, administered one day prior, is the most commonly used preparation method. ${ }^{64}$ To date, there has been no consensus regarding optimal timing of bowel preparation for small bowel CE. ${ }^{65}$ Therefore, a large, multicenter randomized controlled trial is needed to clarify the optimal timing of bowel preparation for small bowel CE. Guidelines for timing of CE bowel preparation are required in the near future.

\section{PROGRESS AND TECHNICAL CHALLENGES IN CE OF THE ENTIRE DIGESTIVE TRACT}

Since CE is non-invasive, it has been applied to other organs, including the esophagus, stomach, and colon. ${ }^{66}$ Main indications for esophageal CE include screening for gastroesophageal reflux disease, Barrett's esophagus, and varices; clinical benefit is, however, unconfirmed.

The stomach is a large luminal organ. CE cannot examine the entire gastric wall just by passive movement of CE. Several small pilot studies of CE in the esophagus or stomach using magnetic manipulation have been reported. ${ }^{67-71}$

Colon CE is one alternative to conventional colonoscopy in symptomatic patients, with a promising potential role in colorectal cancer screening. According to a meta-analysis of the first-generation PillCam COLON, the capsule's sensitivity for detecting patients with polyps and significant colonic findings compares favorably with other colorectal cancer imaging strategies such as CT colonography (CTC) or barium enema. ${ }^{72}$ Recent preliminary data suggest that colon CE is a reasonable method for visualization of colon mucosa in patients with incomplete colonoscopy but without stenosis. According to a recent study of colon CE vs. CTC in patients with incomplete colonoscopy, colon CE and CTC demonstrated similar utility for completing colon evaluation after an incomplete study. ${ }^{73}$ Diagnostic yield of colon CE overall was superior to CTC.

The Agile patency capsule (Given Imaging, Yokneam, Israel) precedes CE to avoid retention of CE. Recently, the radiofrequency identification (RFID) tagless patency capsule was introduced into clinical practice. Use of the tagless capsule confirmed GI tract patency in patients without stenosis on an imaging study, and permitted estimation of the patency in patients with stenosis on imaging. ${ }^{74}$

\section{FUTURE DIRECTIONS OF CE: WHAT TOOLS DO WE NEED IN CLINICAL PRACTICE}

The main challenges in CE are the development of new devices with the ability to provide therapy, air inflation for better visualization of the small bowel, biopsy sampling systems attached to the capsule, and the possibility of guiding and moving the capsule by an external motion controller. Currently, localization is the primary limitation of CE to overcome. Based on transit time, recently proposed software 
and hardware will offer a solution. ${ }^{75}$

\section{CONCLUSIONS}

CE has advanced considerably since the small bowel capsule was introduced 15 years ago. $\mathrm{CE}$ is no longer just for the small bowel. With the advancement of CE technology, the indications for use will expand gradually and diagnostic yield will improve. The investigation of the esophagus, stomach, and colon will be feasible and safe, and will offer benefits in terms of patient preference.

\section{REFERENCES}

1. Iddan G, Meron G, Glukhovsky A, Swain P. Wireless capsule endoscopy. Nature 2000;405:417.

2. Mishkin DS, Chuttani R, Croffie J, et al. ASGE technology status evaluation report: wireless capsule endoscopy. Gastrointest Endosc 2006;63:539-545.

3. Nadler M, Eliakim R. The role of capsule endoscopy in acute gastrointestinal bleeding. Therap Adv Gastroenterol 2014;7:8792.

4. Van de Bruaene C, De Looze D, Hindryckx P. Small bowel capsule endoscopy: where are we after almost 15 years of use? World J Gastrointest Endosc 2015;7:13-36.

5. Pioche M, Gaudin JL, Filoche B, et al. Prospective, randomized comparison of two small-bowel capsule endoscopy systems in patients with obscure GI bleeding. Gastrointest Endosc 2011;73:1181-1188.

6. Dolak W, Kulnigg-Dabsch S, Evstatiev R, Gasche C, Trauner M, Püspök A. A randomized head-to-head study of small-bowel imaging comparing MiroCam and EndoCapsule. Endoscopy 2012;44:1012-1020.

7. Shim KN, Moon JS, Chang DK, et al. Guideline for capsule endoscopy: obscure gastrointestinal bleeding. Clin Endosc 2013;46:45-53.

8. Song HJ, Moon JS, Do JH, et al. Guidelines for bowel preparation before video capsule endoscopy. Clin Endosc 2013;46:147154.

9. Park SK, Ye BD, Kim KO, et al. Guidelines for video capsule endoscopy: emphasis on Crohn's disease. Clin Endosc 2015;48:128-135.

10. Pennazio M, Spada C, Eliakim R, et al. Small-bowel capsule endoscopy and device-assisted enteroscopy for diagnosis and treatment of small-bowel disorders: European Society of Gastrointestinal Endoscopy (ESGE) Clinical Guideline. Endoscopy 2015;47:352-376.
11. Liu K, Kaffes AJ. Review article: the diagnosis and investigation of obscure gastrointestinal bleeding. Aliment Pharmacol Ther 2011;34:416-423.

12. Keum B, Chun HJ. Capsule endoscopy and double balloon enteroscopy for obscure gastrointestinal bleeding: which is better? J Gastroenterol Hepatol 2011;26:794-795.

13. Teshima CW. Small bowel endoscopy for obscure GI bleeding. Best Pract Res Clin Gastroenterol 2012;26:247-261.

14. Min YW, Kim JS, Jeon SW, et al. Long-term outcome of capsule endoscopy in obscure gastrointestinal bleeding: a nationwide analysis. Endoscopy 2014;46:59-65.

15. Seven G, Kozarek RA, Ross A, et al. Double balloon enteroscopy in a North American setting: a large single center 5-year experience. Intest Res 2013;11:34-40.

16. Rondonotti E, Sunada K, Yano T, Paggi S, Yamamoto H. Doubleballoon endoscopy in clinical practice: where are we now? Dig Endosc 2012;24:209-219.

17. Choi DH, Jeon SR, Kim JO, et al. Double-balloon enteroscopy in elderly patients: is it safe and useful? Intest Res 2014;12:313319.

18. Teshima CW, Kuipers EJ, van Zanten SV, Mensink PB. Double balloon enteroscopy and capsule endoscopy for obscure gastrointestinal bleeding: an updated meta-analysis. J Gastroenterol Hepatol 2011;26:796-801.

19. Goddard AF, James MW, McIntyre AS, Scott BB; British Society of Gastroenterology. Guidelines for the management of iron deficiency anaemia. Gut 2011;60:1309-1316.

20. Muhammad A, Vidyarthi G, Brady P. Role of small bowel capsule endoscopy in the diagnosis and management of iron deficiency anemia in elderly: a comprehensive review of the current literature. World J Gastroenterol 2014;20:8416-8423.

21. Garrido Durán C, Iyo Miyashiro E, Páez Cumpa C, Khorrami Minaei S, Erimeiku Barahona A, Llompart Rigo A. Diagnostic yield of video capsule endoscopy in premenopausal women with iron-deficiency anemia. Gastroenterol Hepatol 2015;38:373-378.

22. Riccioni ME, Urgesi R, Spada C, et al. Unexplained iron deficiency anaemia: is it worthwhile to perform capsule endoscopy? Dig Liver Dis 2010;42:560-566.

23. Sidhu PS, McAlindon ME, Drew K, Sidhu R. Diagnostic yield of small-bowel capsule endoscopy in patients with iron deficiency anemia: does it affect management? Gastrointest Endosc 2013;78:800-801.

24. Koulaouzidis A, Yung DE, Lam JH, Smirnidis A, Douglas S, Plevris JN. The use of small-bowel capsule endoscopy in irondeficiency anemia alone; be aware of the young anemic patient. Scand J Gastroenterol 2012;47:1094-1100. 
25. May A, Manner H, Schneider M, Ipsen A, Ell C. Prospective multicenter trial of capsule endoscopy in patients with chronic abdominal pain, diarrhea and other signs and symptoms (CEDAP-Plus Study). Endoscopy 2007;39:606-612.

26. Shim KN, Kim YS, Kim KJ, et al. Abdominal pain accompanied by weight loss may increase the diagnostic yield of capsule endoscopy: a Korean multicenter study. Scand J Gastroenterol 2006;41:983-988.

27. Rosa B, Moreira MJ, Rebelo A, Cotter J. Lewis Score: a useful clinical tool for patients with suspected Crohn's disease submitted to capsule endoscopy. J Crohns Colitis 2012;6:692-697.

28. Kopylov U, Nemeth A, Koulaouzidis A, et al. Small bowel capsule endoscopy in the management of established Crohn's disease: clinical impact, safety, and correlation with inflammatory biomarkers. Inflamm Bowel Dis 2015;21:93-100.

29. Adler SN, Yoav M, Eitan S, Yehuda C, Eliakim R. Does capsule endoscopy have an added value in patients with perianal disease and a negative work up for Crohn's disease? World J Gastrointest Endosc 2012;4:185-188.

30. Koulaouzidis A, Douglas S, Rogers MA, Arnott ID, Plevris JN. Fecal calprotectin: a selection tool for small bowel capsule endoscopy in suspected IBD with prior negative bi-directional endoscopy. Scand J Gastroenterol 2011;46:561-566.

31. Koulaouzidis A, Douglas S, Plevris JN. Lewis score correlates more closely with fecal calprotectin than capsule endoscopy Crohn's disease activity index. Dig Dis Sci 2012;57:987-993.

32. Leighton JA, Gralnek IM, Cohen SA, et al. Capsule endoscopy is superior to small-bowel follow-through and equivalent to ileocolonoscopy in suspected Crohn's disease. Clin Gastroenterol Hepatol 2014;12:609-615.

33. Gal E, Geller A, Fraser G, Levi Z, Niv Y. Assessment and validation of the new capsule endoscopy Crohn's disease activity index (CECDAI). Dig Dis Sci 2008;53:1933-1937.

34. Niv Y, Ilani S, Levi Z, et al. Validation of the capsule endoscopy Crohn's disease activity index (CECDAI or Niv score): a multicenter prospective study. Endoscopy 2012;44:21-26.

35. Gralnek IM, Defranchis R, Seidman E, Leighton JA, Legnani P, Lewis BS. Development of a capsule endoscopy scoring index for small bowel mucosal inflammatory change. Aliment Pharmacol Ther 2008;27:146-154.

36. Cotter J, Dias de Castro F, Magalhães J, Moreira MJ, Rosa B. Validation of the Lewis score for the evaluation of small-bowel Crohn's disease activity. Endoscopy 2015;47:330-335.

37. Swaminath A, Legnani P, Kornbluth A. Video capsule endoscopy in inflammatory bowel disease: past, present, and future redux. Inflamm Bowel Dis 2010;16:1254-1262.
38. Liao Z, Gao R, Xu C, Li ZS. Indications and detection, completion, and retention rates of small-bowel capsule endoscopy: a systematic review. Gastrointest Endosc 2010;71:280-286.

39. Cheifetz AS, Kornbluth AA, Legnani P, et al. The risk of retention of the capsule endoscope in patients with known or suspected Crohn's disease. Am J Gastroenterol 2006;101:2218-2222.

40. Höög CM, Bark LÅ, Arkani J, Gorsetman J, Broström O, Sjöqvist U. Capsule retentions and incomplete capsule endoscopy examinations: an analysis of 2300 examinations. Gastroenterol Res Pract 2012;2012:518718. doi: 10.1155/2012/518718.

41. Rondonotti E, Soncini M, Girelli C, et al. Small bowel capsule endoscopy in clinical practice: a multicenter 7-year survey. Eur J Gastroenterol Hepatol 2010;22:1380-1386.

42. Esaki M, Matsumoto T, Watanabe K, et al. Use of capsule endoscopy in patients with Crohn's disease in Japan: a multicenter survey. J Gastroenterol Hepatol 2014;29:96-101.

43. Panes J, Bouhnik Y, Reinisch W, et al. Imaging techniques for assessment of inflammatory bowel disease: joint ECCO and ESGAR evidence-based consensus guidelines. J Crohns Colitis 2013;7:556-585

44. Herrerias JM, Leighton JA, Costamagna G, et al. Agile patency system eliminates risk of capsule retention in patients with known intestinal strictures who undergo capsule endoscopy. Gastrointest Endosc 2008;67:902-909.

45. Koulaouzidis A, Rondonotti E, Giannakou A, Plevris JN. Diagnostic yield of small-bowel capsule endoscopy in patients with iron-deficiency anemia: a systematic review. Gastrointest Endosc 2012;76:983-992.

46. Cheung DY, Lee IS, Chang DK, et al. Capsule endoscopy in small bowel tumors: a multicenter Korean study. J Gastroenterol Hepatol 2010;25:1079-1086.

47. Shyung LR, Lin SC, Shih SC, Chang WH, Chu CH, Wang TE. Proposed scoring system to determine small bowel mass lesions using capsule endoscopy. J Formos Med Assoc 2009;108:533-538.

48. Lim YJ, Chun HJ. Recent advances in NSAIDs-induced enteropathy therapeutics: new options, new challenges. Gastroenterol Res Pract 2013;2013:761060. doi: 10.1155/2013/761060.

49. Shim KN, Song EM, Jeen YT, et al. Long-term outcomes of NSAID-induced small intestinal injury assessed by capsule endoscopy in Korea: a nationwide multicenter retrospective study. Gut Liver 2015;9:727-733.

50. De Palma GD, Rega M, Masone S, et al. Mucosal abnormalities of the small bowel in patients with cirrhosis and portal hypertension: a capsule endoscopy study. Gastrointest Endosc 2005;62:529-534. 
51. Jeon SR, Kim JO, Kim JB, et al. Portal hypertensive enteropathy diagnosed by capsule endoscopy in cirrhotic patients: a nationwide multicenter study. Dig Dis Sci 2014;59:1036-1041.

52. Aoyama T, Oka S, Aikata H, et al. Major predictors of portal hypertensive enteropathy in patients with liver cirrhosis. J Gastroenterol Hepatol 2015;30:124-130.

53. Mustalahti K, Catassi C, Reunanen A, et al. The prevalence of celiac disease in Europe: results of a centralized, international mass screening project. Ann Med 2010;42:587-595.

54. Ludvigsson JF, Rubio-Tapia A, van Dyke CT, et al. Increasing incidence of celiac disease in a North American population. Am J Gastroenterol 2013;108:818-824.

55. Jones HJ, Warner JT. NICE clinical guideline 86. Coeliac disease: recognition and assessment of coeliac disease. Arch Dis Child 2010;95:312-313.

56. Petroniene R, Dubcenco E, Baker JP, et al. Given capsule endoscopy in celiac disease: evaluation of diagnostic accuracy and interobserver agreement. Am J Gastroenterol 2005;100:685-694.

57. Hopper AD, Sidhu R, Hurlstone DP, McAlindon ME, Sanders DS. Capsule endoscopy: an alternative to duodenal biopsy for the recognition of villous atrophy in coeliac disease? Dig Liver Dis 2007;39:140-145.

58. Lidums I, Cummins AG, Teo E. The role of capsule endoscopy in suspected celiac disease patients with positive celiac serology. Dig Dis Sci 2011;56:499-505.

59. Rondonotti E, Spada C, Cave D, et al. Video capsule enteroscopy in the diagnosis of celiac disease: a multicenter study. Am J Gastroenterol 2007;102:1624-1631.

60. Gweon TG, Lim CH, Byeon SW, et al. A case of celiac disease. Korean J Gastroenterol 2013;61:338-342.

61. Tursi A. Endoscopic diagnosis of celiac disease: what is the role of capsule endoscopy? Gastrointest Endosc 2013;78:381.

62. Xue M, Chen X, Shi L, Si J, Wang L, Chen S. Small-bowel capsule endoscopy in patients with unexplained chronic abdominal pain: a systematic review. Gastrointest Endosc 2015;81:186-193.

63. Katsinelos P, Fasoulas K, Beltsis A, et al. Diagnostic yield and clinical impact of wireless capsule endoscopy in patients with chronic abdominal pain with or without diarrhea: a Greek multicenter study. Eur J Intern Med 2011;22:e63-e66.

64. Koulaouzidis A, Rondonotti E, Karargyris A. Small-bowel capsule endoscopy: a ten-point contemporary review. World J Gastroenterol 2013;19:3726-3746.
65. Mathus-Vliegen E, Pellisé M, Heresbach D, et al. Consensus guidelines for the use of bowel preparation prior to colonic diagnostic procedures: colonoscopy and small bowel video capsule endoscopy. Curr Med Res Opin 2013;29:931-945.

66. Hosoe N, Naganuma M, Ogata H. Current status of capsule endoscopy through a whole digestive tract. Dig Endosc 2015;27:205-215.

67. Keller J, Fibbe C, Volke F, et al. Remote magnetic control of a wireless capsule endoscope in the esophagus is safe and feasible: results of a randomized, clinical trial in healthy volunteers. Gastrointest Endosc 2010;72:941-946.

68. Keller J, Fibbe C, Volke F, et al. Inspection of the human stomach using remote-controlled capsule endoscopy: a feasibility study in healthy volunteers (with videos). Gastrointest Endosc 2011;73:22-28.

69. Swain P, Toor A, Volke F, et al. Remote magnetic manipulation of a wireless capsule endoscope in the esophagus and stomach of humans (with videos). Gastrointest Endosc 2010;71:12901293.

70. Morita E, Ohtsuka N, Shindo Y, et al. In vivo trial of a driving system for a self-propelling capsule endoscope using a magnetic field (with video). Gastrointest Endosc 2010;72:836-840.

71. Kim HM, Choi JS, Cho JH. A pilot trial of ambulatory monitoring of gastric motility using a modified magnetic capsule endoscope. J Neurogastroenterol Motil 2014;20:261-264.

72. Spada C, Hassan C, Marmo R, et al. Meta-analysis shows colon capsule endoscopy is effective in detecting colorectal polyps. Clin Gastroenterol Hepatol 2010;8:516-522.

73. Spada C, Hassan C, Barbaro B, et al. Colon capsule versus CT colonography in patients with incomplete colonoscopy: a prospective, comparative trial. Gut 2015;64:272-281.

74. Nakamura M, Hirooka Y, Yamamura T, et al. Clinical usefulness of novel tag-less Agile patency capsule prior to capsule endoscopy for patients with suspected small bowel stenosis. Dig Endosc 2015;27:61-66.

75. Koulaouzidis A, Iakovidis DK, Karargyris A, Plevris JN. Optimizing lesion detection in small-bowel capsule endoscopy: from present problems to future solutions. Expert Rev Gastroenterol Hepatol 2015;9:217-235. 